\title{
SOCIAL CRISIS, PROTESTS AND EFFECTS ON PUBLIC EMERGENCY SERVICES: ECONOMETRIC ANALYSIS OF THE CHILEAN SOCIAL OUTBREAK
}

\author{
VALERIA SCAPINI ${ }^{1}$, CINTHYA VERGARA ${ }^{2} \&$ JASMINA CONTRERAS $^{1}$ \\ ${ }^{1}$ Centro de Investigación en Innovación, Desarrollo Económico y Políticas Sociales (CIDEP), \\ Universidad de Valparaíso, Chile \\ ${ }^{2}$ Universidad Chile, Chile
}

\begin{abstract}
Chile is known for being one of the richest and most stable countries in Latin America, however it is also the most unequal country in the Organization for Economic Cooperation and Development (OECD) with an income gap that is $65 \%$ higher than the OECD average. This situation has generated, for more than a decade, protests to improve living conditions. Citizens, seeing no response from the authorities and faced with a 30-peso hike in the public transport rate in October 2019, went out to protest with greater intensity, generating a large-scale social unrest, producing a series of demonstrations throughout the country where there were violent clashes with the police that ended with the application of toxic gases and riot guns, as measures of repression. The purpose of this work is to determine the impact that the demonstrations had on the number of admission to emergency care in public health centres, through a difference-in-differences analysis where two municipalities are compared, one that was exposed to demonstrations and disorders daily, while the other was not. The results are statistically significant and indicate that there was a $4 \%$ increase in the number of emergency care visits, and a $7 \%$ increase in the number of care for respiratory symptoms in health centres located in the municipality that was exposed to manifestations and public disorder. Finally, the results can be useful to dialogue and discuss "the protocols of police action in Chile" and take into account the health-related effects on citizens and their impact on other public services.
\end{abstract}

Keywords: socio-economic crisis, manmade disasters, social outbreak, citizen protests, public health management.

\section{INTRODUCTION}

From the beginning of its history, Chile has proven to be a country with great socio-economic inequalities, reflected both in income differences and geographical segregation by social segment [1]. During 2019, it is estimated that the richest $1 \%$ capture close to $17 \%$ of tax revenues, while the richest $10 \%$ receive more than $50 \%$ of all income and, considering the undistributed profits of the companies (retained earnings within firms), $1 \%$ of the population receive around $24 \%$ of all income generated [2]. Additionally, and according to the GINI index, Chile has remained the most unequal country within the OECD countries [3].

However, the government authorities, led by President Sebastian Piñera, celebrated the country's economic growth as a success of their management with great optimism, while the unemployment rate was growing [4], [5] together with the prices of basic services, and in general the living cost [6]. In this scenario and after a 30-peso hike in the cost of public transport fares, Chilean citizens, mainly high school students, began a series of protests calling to evade the payment of public transportation tickets. On 14 October, facing a lack of response from the authorities to solve economic problems and excessive police violence, spontaneously, many cities in the country came out to protest, generating one of the largest protests, most massive and extensive geographical areas in the country's history, marking the beginning of a period of periodic demonstrations marked by strong confrontations between 
the police and protesters, leading even to cases of death and mutilation, particularly of the eyes [7], [8].

Under this context, it is hypothesized that an increase in emergency care was generated in the public health services in the main area of demonstrations in the capital, known as demonstrations of the "Chilean Social Outbreak". With this, this research seeks to quantify the effect of the social outbreak on the admission of emergency care visits to the public health centres of two municipalities of the Metropolitan Region: the municipality of Santiago and the municipality of La Florida, selected because of their similarity in socioeconomic aspects, where both municipalities have a low social priority classification in the Metropolitan Region, ranking 41st and 42nd [9] and a similar population with 404,495 and 366,916 inhabitants each [10], respectively.

By applying the difference-in-difference method, the impact of the social outbreak (exogenous shock) is studied, using income data from a total of 18 public emergency care centres before and after the event, in order to determine the percentage variation. Finally, the results are expected to provide information on the effects of the demonstrations on emergency care and, thereby, improve the riot, demonstration, or protest management, police protocols and reactions to imbalances that are generated in the health system.

\section{CHILEAN CONTEXT: CHILEAN SOCIAL OUTBREAK}

After a period with increases in the cost of living, an increase in unemployment in addition to the historical inequality in the distribution of income that has marked the history of Chile [1], on 14 October 2019, there was a large-scale demonstration throughout the country, with cross-sectional citizen support, which started the so-called "Chilean Social Outbreak". This period, characterized by large mobilizations and protests, prompted the questioning of the Chilean socio-economic model and generated, as one of the main results, the beginning of a constitutional reform process.

However, the process was not free of costs neither for the citizens nor for the government. According to the updated data of the National Institute of Human Rights as of 19 March 2020, as a result of the police action, 3,878 injured people were registered in health centres. The origin of the injuries is broken down as follows: bale 53, pellet 193, shots 1,687, tear gas 298, blows 1,411 and unidentified causes 196 [10]. Of which 460 people have eye injuries. Where eye trauma ranges from irritation or inflammation of the conjunctiva to loss of the eyeball, trauma that affects various parts of the body. In addition, the use of tear gas, which has been questioned for its harmful effects on the respiratory system, not only causes a transitory effect, but also a long-term effect, which may cause in some people; pulmonary oedema, laryngospasm and reactive dysfunction, up to ten months after exposure to riot control agents, reaching in extreme situations to trigger the death of the person. To date, around 36 deaths linked to the protests have been declared [7], [11]-[13].

Some cases are known that have shocked society; like the young photographer Gustavo Gatica, who lost both eyes after being wounded by police pellets in a protest. Or the case of Fabiola Campillay, a young woman who was hit by a tear gas canister while waiting for the bus on her way to work, resulting in a loss of sight. Also the case of Abel Acuña, a young man with a heart history who died after suffering a cardiorespiratory arrest as a result of tear gas canisters. The inappropriate use of riot control agents as a dispersal measure to control protest actions has serious consequences for those exposed to the demonstrations, both directly and indirectly.

Since mid-October 2019, protests and greater social unrest have continued, which, in turn, have generated an increase in emergency care [14]. In the period from 18 October to 18 December 2019, throughout the country 13,046 people attended emergency services, of 
which 4,784 people belong to the metropolitan region, reaching $37 \%$ of the total number of care cases and the remaining $63 \%$ belonging to other regions with 8,262 people served [15]. Figs 1 and 2 show some emblematic images of what happened.

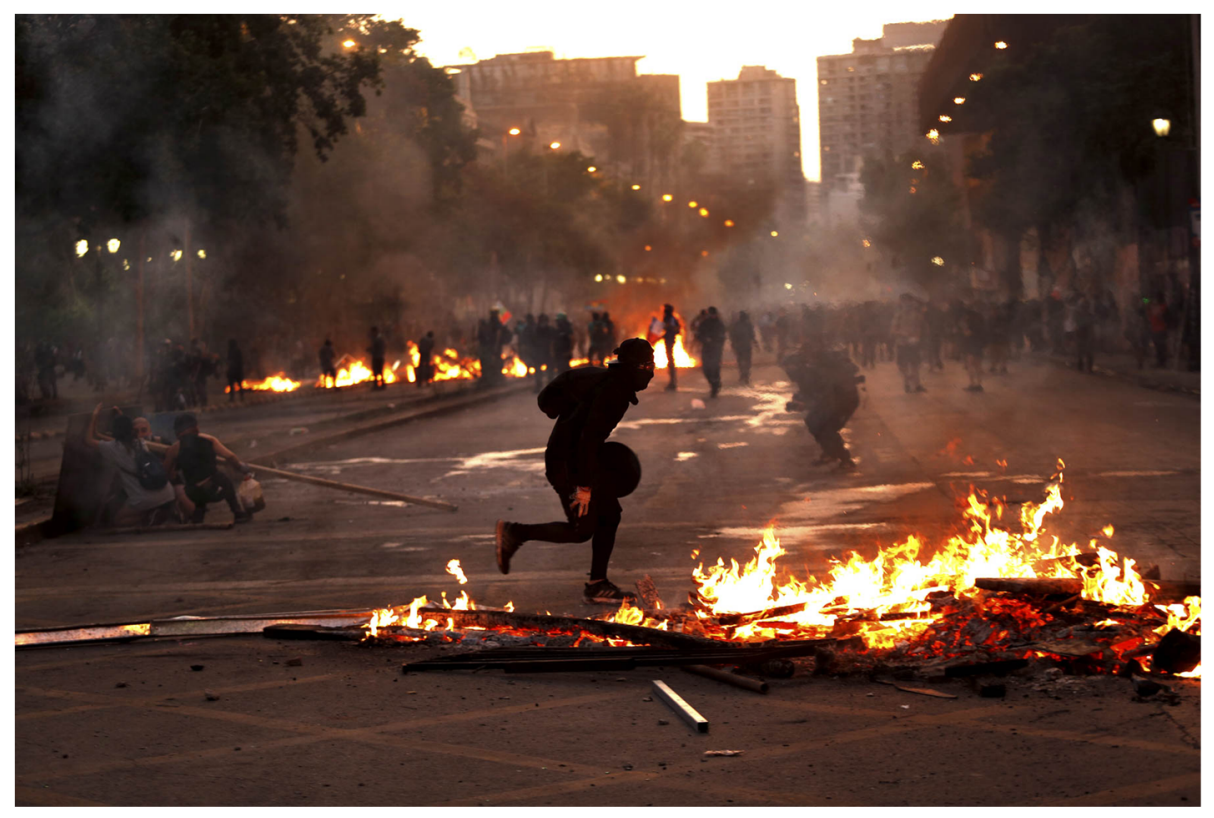

Figure 1: Chile Protest - Image of Chile woke up [16].

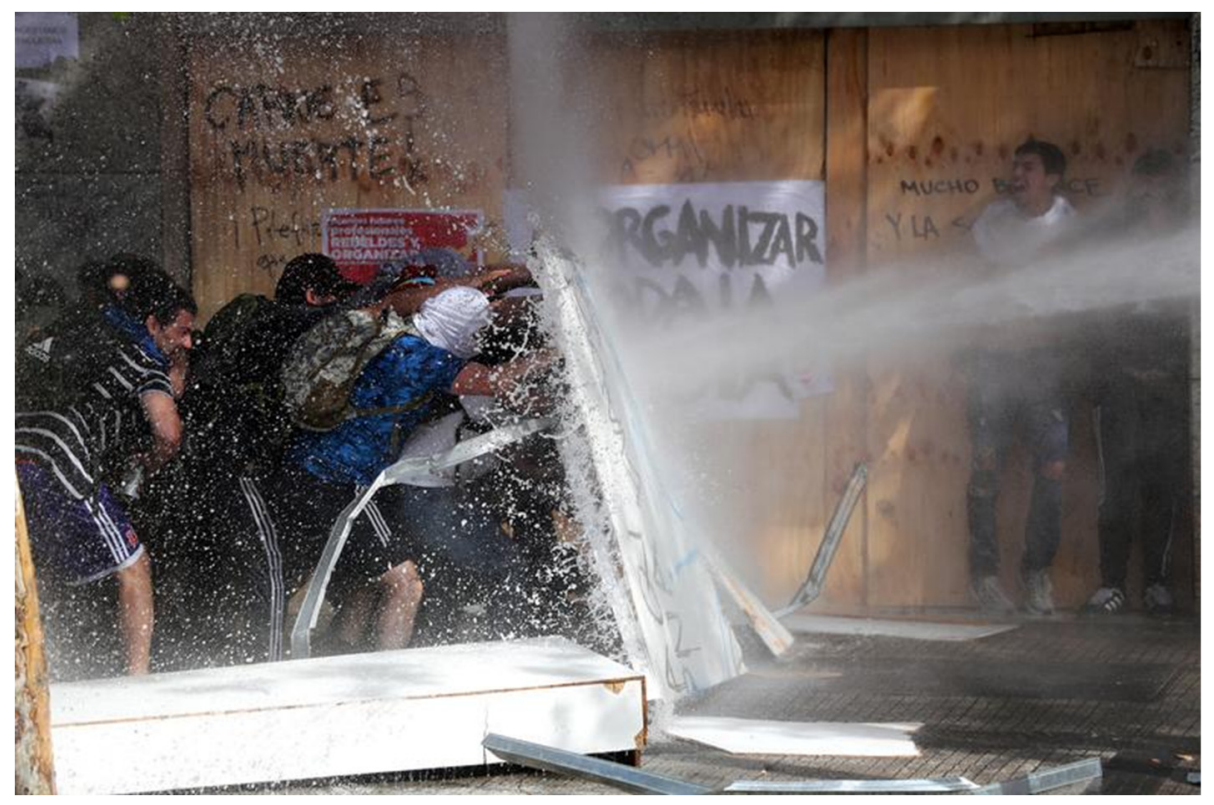

Figure 2: Protesters take cover as security forces spray them with a water cannon [17]. 
In this scenario, it is of interest to quantify the variation in care in percentage terms and to identify if there is any level of impact on public health services. With the results of this analysis, it is expected to provide input for the government's management to develop and exercise public policies, to focus programs, projects and resources in those areas that present greater relative deficiencies to be able to face emergency care on days of demonstrations.

\section{METHODOLOGY}

To study the effect of social movement, demonstrations and subsequent public disorder over the number of admissions to public health services, the difference-in-differences model, also known as double difference, was used. This model assumes that the occurrence of the treatment, which in this case is the social movement event, is an exogenous variation and that it is not related to other events that occur in the affected area. It requires the comparison of two groups, one that has been affected by exogenous variation, known as the treatment group or affected area, and the other group that has not been affected, known as the control group or unaffected area. The technique compares two groups during the same time period, and the groups are observed before and after the change. The estimator measures the difference that exists between both groups, and in both periods of time.

Considering the above, the two groups to be compared were selected. The first of them corresponds to the municipality of Santiago, capital of the province of Santiago, established in 1928. It is known as Santiago Centro because it is located in the central sector of the city. It houses the historic centre and the main state agencies. This area was selected as a Treatment group since it was exposed to daily demonstrations that mostly ended with disorders during the period after the social movement. Second, the municipality of La Florida, located in the south-eastern sector of the city of Santiago, is a residential zone made up of families of medium socioeconomic level. During the 1980s and part of the 1990s, it was the most populated municipality in the country and is currently the fourth nationwide [18]. This municipality was selected as a Control group since no major disorders were recorded in the period after the occurrence of the treatment. Fig. 3 shows a map that refers to the location of both municipalities:

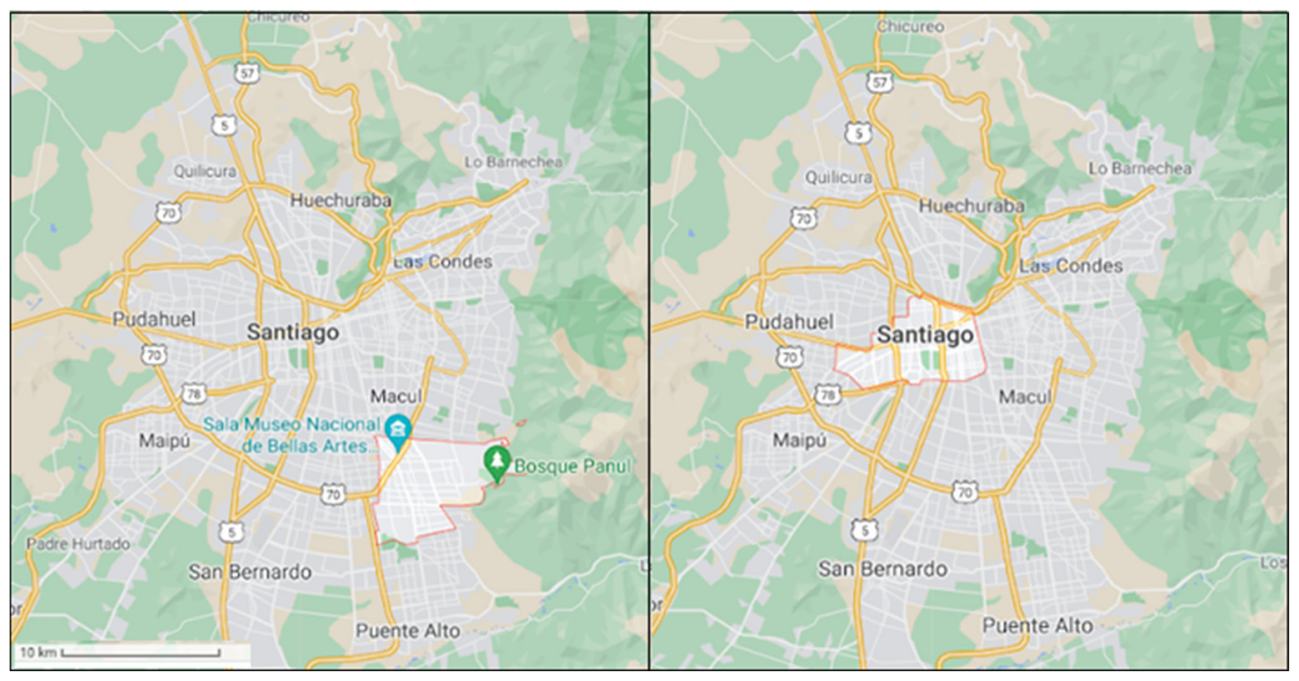

Figure 3: Location of the municipalities of Santiago (right) and La Florida (left). 
Two models were estimated where the variable of interest for the first estimate is the total urgent care (1), while in the second the explained variable is the total respiratory care (2). In both cases, the estimated model corresponds to a difference-in-difference specification that aims to determine the effect of disorders on public emergency services, more explicitly:

$$
\begin{aligned}
& \text { Emergency }_{i t}=\beta_{i t}+\beta_{1} \text { Affected }_{i}+\beta_{2} \text { Post }_{t}+\beta_{3} \text { Affected }_{i} * \text { Post }_{t}+\epsilon_{i t}, \\
& \text { Respiratory }_{i t}=\beta_{i t}+\beta_{1} \text { Affected }_{i}+\beta_{2} \text { Post }_{t}+\beta_{3} \text { Affected }_{i} * \text { Post }_{t}+\epsilon_{i t} .
\end{aligned}
$$

The dependent variable in the first model (1) is the number of emergency care services worked in logarithmic scale, $i$ corresponds to the municipality and $t$ to the day of the week. Affected is a binary variable that indicates whether the municipality was exposed to demonstrations or not. Post corresponds to a binary variable that takes the value 1 if it corresponds to the period of time after 18 October 2019 and 0 otherwise. Finally, the coefficient $\beta_{3}$ represents the difference between the affected and unaffected area in the period after the event, that is, it shows the impact to be measured. The estimation includes a fixed effect per day and centre of departure, thus controlling for all time- and space-varying differences. In the second model (2), the dependent variable is the total number of respiratory visits worked on a logarithmic scale, and the independent variables are the same as in the previous model.

To validate the results obtained, subsequently, a forgery analysis was performed. To carry out this test, the event was instrumentally moved to a previous moment in time. The data used were obtained from the website of the Department of Statistics of the Ministry of Health of Chile (known as DEIS), corresponding to the total number of emergency care visits and the number of care visits for respiratory symptoms of the 18 public health centres that exist in the municipalities under study. This information was downloaded from 1 January 2019 to 31 December of the same year, and was worked on a daily level, which obtained a data set that contains 5,421 records for the total urgent care and 5,045 observations for total respiratory care.

\section{RESULTS}

The model estimated according to eqn (1) shows that, during the period after 14 October 2019 , in the municipality of Santiago, the number of emergency services actually increased due to the demonstrations. This can be seen in the coefficient $\beta_{3}$ that accompanies the Affected $\times$ Post interaction with a positive sign. Taking this coefficient, it is possible to estimate that the disturbances in the municipality of Santiago increases the percentage of emergency attention by $5 \%$ in relation to the municipality of La Florida, ceteris paribus. However, this increase is not statistically significant (see in the first column of Table 1).

By including the control variables, the estimated model shows a better fit in its output, increasing from $R^{2}=0.1409$ to $R^{2}=0.7917$ and, on the other hand, the variable of interest remains positive and turns significant. This allows a conclusion that the occurrence of demonstrations in the municipality of Santiago generates an increase in the percentage of emergency attention of $4 \%$ concerning the municipality where there were less or no impacts due to demonstrations.

The second estimated model (eqn 2) shows that, after the occurrence of the social movement, demonstrations and subsequent disorders in the municipality of Santiago, the number of care visits for respiratory symptoms cases increased, that is, the Affected $\times$ Post interaction variable has a positive sign, although not significant (see in the third column 
Table 1: Differences in differences results.

\begin{tabular}{|l|c|c|c|c|}
\hline \multirow{3}{*}{ Variables } & $\mathbf{( 1 )}$ & $\mathbf{( 2 )}$ & $\mathbf{( 3 )}$ & $\mathbf{( 4 )}$ \\
\cline { 2 - 5 } & $\begin{array}{c}\text { Total } \\
\text { emergency }\end{array}$ & $\begin{array}{c}\text { Total } \\
\text { emergency }\end{array}$ & $\begin{array}{c}\text { Total } \\
\text { respiratory }\end{array}$ & $\begin{array}{c}\text { Total } \\
\text { respiratory }\end{array}$ \\
\hline \multirow{2}{*}{ Affected } & $0.386172^{* * *}$ & $0.486920^{* * *}$ & -0.029347 & $-3.71503^{* * *}$ \\
& $(0.0158139)$ & $(.0200296)$ & $(.0263038)$ & $(0.4216872)$ \\
\hline \multirow{2}{*}{ Post } & $-0.18881^{* * *}$ & $0.145206^{* *}$ & $-0.642340^{* * *}$ & 0.168266 \\
& $(0.0222594)$ & $(0.1005198)$ & $(0.0350571)$ & $(0.1633352)$ \\
\hline \multirow{2}{*}{ Affected x Post } & 0.0528024 & $0.042850^{* *}$ & 0.067580 & $0.071099^{* *}$ \\
& $(0.0349906)$ & $(0.0178686)$ & $(.0582259)$ & $(0.0295997)$ \\
\hline$R^{2}$ & 0.1409 & 0.7917 & 0.0884 & 0.7823 \\
\hline No. of observations & 5,421 & 5,421 & 5,045 & 5,045 \\
\hline F.E. Day & No & Yes & No & Yes \\
\hline E.F. Health Centre & No & Yes & No & Yes \\
\hline
\end{tabular}

Note: Robust standard errors in parentheses.

* Significant at $10 \%$; * significant at $5 \% ; * * *$ significant at $1 \%$.

of Table 1). The goodness of fit of the model improves from $R^{2}=0.0884$ to $R^{2}=$ 0.7823 when the control variables health centres and date were included, and the output turns significant, which allows for the conclusion that the occurrence of demonstrations in the municipality of Santiago increases the percentage of respiratory attention by $7 \%$ concerning the municipality of La Florida. Results of the estimates made are shown in Table 1.

Finally, to obtain a robust analysis, a falsification test was included. Hereby, among the health establishments of the municipality not affected by movements, a comparison of the number of emergency care cases and the number of care for respiratory symptoms cases were divided into two groups, the north zone and the south zone. In Table 2 it can be observed that the interaction variable is not significant when making the comparison. In other words, there are no differences between the health centres in the northern and southern areas, before and after the social outbreak.

Table 2: Falsification test.

\begin{tabular}{|l|c|c|c|c|}
\hline \multirow{3}{*}{ Variables } & $\mathbf{( 1 )}$ & $\mathbf{( 2 )}$ & $\mathbf{( 3 )}$ & $\mathbf{( 4 )}$ \\
\cline { 2 - 5 } & $\begin{array}{c}\text { Total } \\
\text { emergency }\end{array}$ & $\begin{array}{c}\text { Total } \\
\text { emergency }\end{array}$ & $\begin{array}{c}\text { Total } \\
\text { respiratory }\end{array}$ & $\begin{array}{c}\text { Total } \\
\text { respiratory }\end{array}$ \\
\hline \multirow{2}{*}{ Affected } & $0.163919^{* * *}$ & $-0.67495^{* * *}$ & $-0.581594^{* * *}$ & $-0.60509^{* * *}$ \\
& $(0.0235045)$ & $(0.0197622)$ & $(0.0304632)$ & $(0.0318757)$ \\
\hline \multirow{2}{*}{ Post } & $-0.172530^{* * *}$ & $-0.288423^{* *}$ & $-0.660001^{* * *}$ & $-0.494822^{* *}$ \\
& $(0.0301096)$ & $(0.1278949)$ & $(0.0388876)$ & $(0.2134879)$ \\
\hline \multirow{2}{*}{ Affected x Post } & -0.0479809 & $-0.0277499^{*}$ & 0.0488766 & 0.0339966 \\
& $(0.0521603)$ & $(0.0237027)$ & $(0.067663)$ & $(0.0384034)$ \\
\hline$R^{2}$ & 0.0340 & 0.8009 & 0.2082 & 0.7459 \\
\hline No. of observations & 3,233 & 3,233 & 3,221 & 3,221 \\
\hline F.E. Day & No & Yes & No & Yes \\
\hline E.F. Health Centre & No & Yes & No & Yes \\
\hline
\end{tabular}

Note: Robust standard errors in parentheses.

* Significant at $10 \%$; * significant at $5 \%$; ** significant at $1 \%$. 
In summary, the obtained output shows that social demonstrations do have an impact on emergency care and respiratory care in the public health network. The effect obtained in the municipalities exposed to demonstrations is positive and significant. Specifically, it increases the total emergency care by $4 \%$ and the total respiratory care by $7 \%$.

\section{CONCLUSIONS}

The study carried out allows us to identify that there is an impact of the social demonstrations that occurred after October 2019 in the emergency public services. The results of the adjusted models allow us to estimate that the increase in care is significant and may reach $4 \%$ in the number of emergency care in the municipality exposed to demonstrations, concerning the municipality not exposed. Similarly, the second model shows a significant $7 \%$ increase in the number of respiratory care visits in the municipality exposed to demonstrations compared to the unexposed municipality.

The significant increase in the demand for care, in days of mobilization and protest that end in confrontations, causes an increase in work for personnel in the public health area and also a greater use of facilities, infrastructure, medicines and supplies for the care of patients. Recognizing these figures is not only relevant to have the information and increase the resources to attend and prevent unexpected or momentary situations, but it is also essential to generate public policies that allow having specialized personnel, better infrastructure and equipment and, in this way, manage and distribute public health resources and move towards equity in access to public health benefits. It is possible to see that the assumption is fulfilled that the increase in respiratory care is due to the harmful effects of riot control agents because it not only affects people exposed to direct action but also those who are confronted passively. With this, it is important that the containment policies carried out by the police take into account the damage they generate in the population in terms of health.

The results obtained can be useful to dialogue, discuss and legislate on "the protocols of police action in Chile" and take into account the health-related effects on citizens and their consequences on other public services.

\section{REFERENCES}

[1] Cociña, M., Desiguales: Orígenes, cambios y desafíos de la brecha social en Chile. Programa de las Naciones Unidas para el Desarrollo (PNUD), 2017.

[2] Sanhueza, C., Atria, J., Flores, I. \& Mayer, R., Top incomes in Chile: A historical perspective on income inequality, 1964-2017. Income and Wealth, 66(4), pp. 850874, 2020.

[3] OECD, Inequality: Income inequality - OECD data, 2021. https://data.oecd.org/ inequality/income-inequality.htm. Accessed on: 12 May 2021.

[4] Fuentes, A., Caracterización del desempleo en Chile. Puntos de Referencia Edición Digital MR, 2019.

[5] Banco Central, Tasa de desempleo, Serie Histórica, 2021. https://si3.bcentral.cl/ Bdemovil/BDE/Series/MOV_SC_ML3. Accessed on: 2 Jun. 2021.

[6] González, A., El costo de la vida en Chile, una de las chispas del estallido social. Santiago, 2019.

[7] McDonald, B., A bullet to the eye is the price of protesting in Chile. New York Times, 19 Nov., 2019.

[8] Rodríguez, Á., et al., Ocular trauma by kinetic impact projectiles during civil unrest in Chile. Nature Eye, 35, pp. 1666-1672, 2021. 
[9] Gajardo Polanco, S., Región Metropolitana de Santiago: Índice de prioridad social de comunas 2019. Seremi de Desarrollo Social y Familia Metropolitana, Santiago, Chile, 2019.

[10] INE, Resultados Censo 2017: Web Diseminación Censo 2017, Instituto Nacional de Estadísticas, Santiago, Chile, 2017.

[11] MINSAL, Balance de Salud de la Red Pública (18 de octubre al 18 de diciembre 2019). https://www.minsal.cl/wp-content/uploads/2019/12/2019.12.20_BALANCEATENCIONES-DE-SALUD_04.pdf. Accessed on: 3 Jun. 2021.

[12] El Periodista, A un año del estallido social: más de 30 muertos y 460 personas con lesiones oculares, Diario El Periodista, Santiago, 2020.

[13] OHCHR, Report of the mission to Chile 30 October-22 November 2019, Office of the High Commissioner for Human Rights. https://www.ohchr.org/Documents/Countries/ CL/Report_Chile_2019_EN.pdf. Accessed on: 12 Apr. 2021.

[14] La Tercera, Con turnos extra y a cuatro pabellones, la UTO del Hospital del Salvador atiende a cientos de pacientes con traumas oculares que dejan los balines, La Tercera, Santiago, Chile, 2019.

[15] La Tercera, Balance de atención de urgencias: Desde el estallido social se han registrado casi 11 mil consultas vinculadas a episodios de violencia, Diario La Tercera, Santiago, Chile, 2019.

[16] Ledur, J. \& Levine, A.J., Chile woke up. Thomson Reuters. www.graphics.reuters.com/CHILE-PROTESTS/0100B32527X/index.html. Accessed on: 12 Apr. 2021.

[17] Lucas, D., Chile declares state of emergency amid riots. Thomson Reuters. www.reuters.com/news/picture/chile-declares-state-of-emergency-amid-ridUSRTS2S1BS. Accessed on: 12 Apr. 2021.

[18] Gajardo, S., Índice de prioridad social de comunas 2019. http://www.desarrollosocialyfamilia.gob.cl/storage/docs/INDICE._DE_PRIORIDAD _SOCIAL_2019.pdf. Accessed on: 16 May 2021. 